
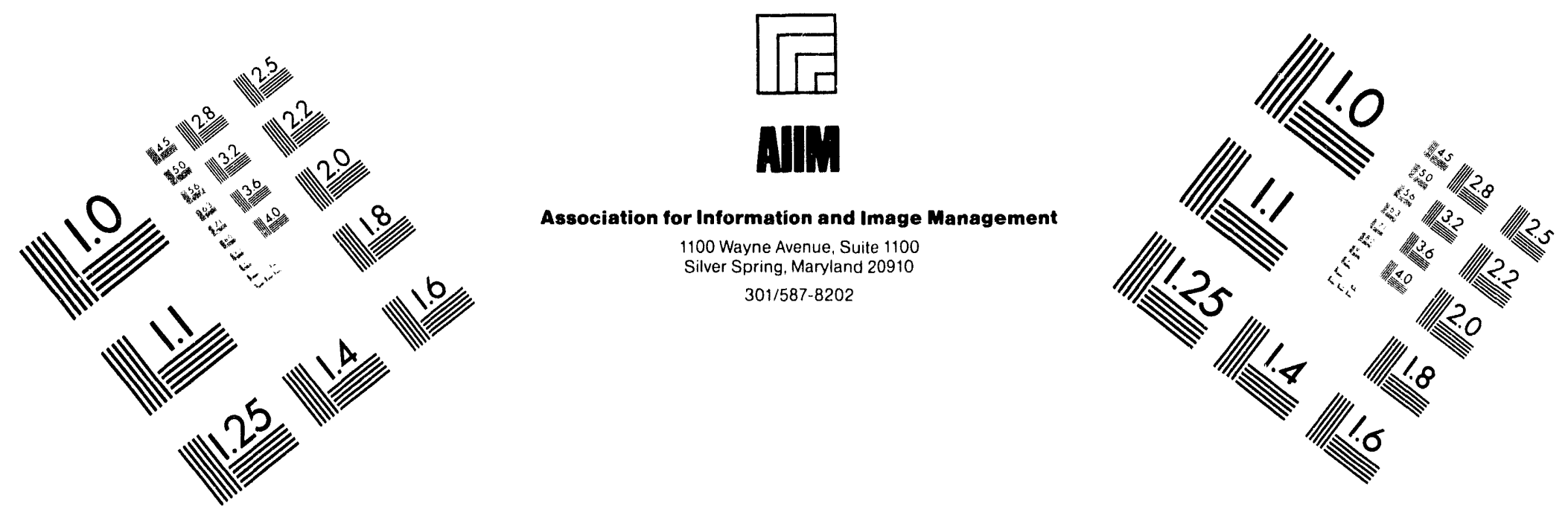

\title{
Centimeter
}

$\begin{array}{llllllllllllllll}1 & 2 & 3 & 4 & 5 & 6 & 7 & 8 & 9 & 10 & 11 & 12 & 13 & 14 & 15 & \mathrm{~mm}\end{array}$

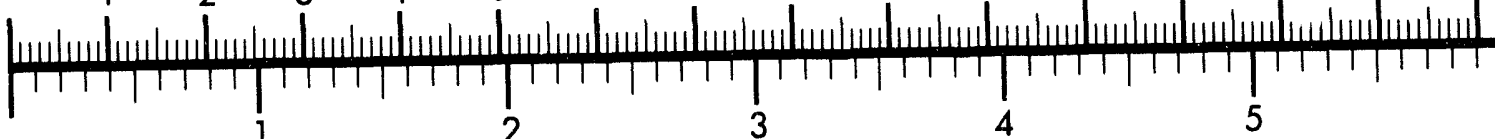
Inches
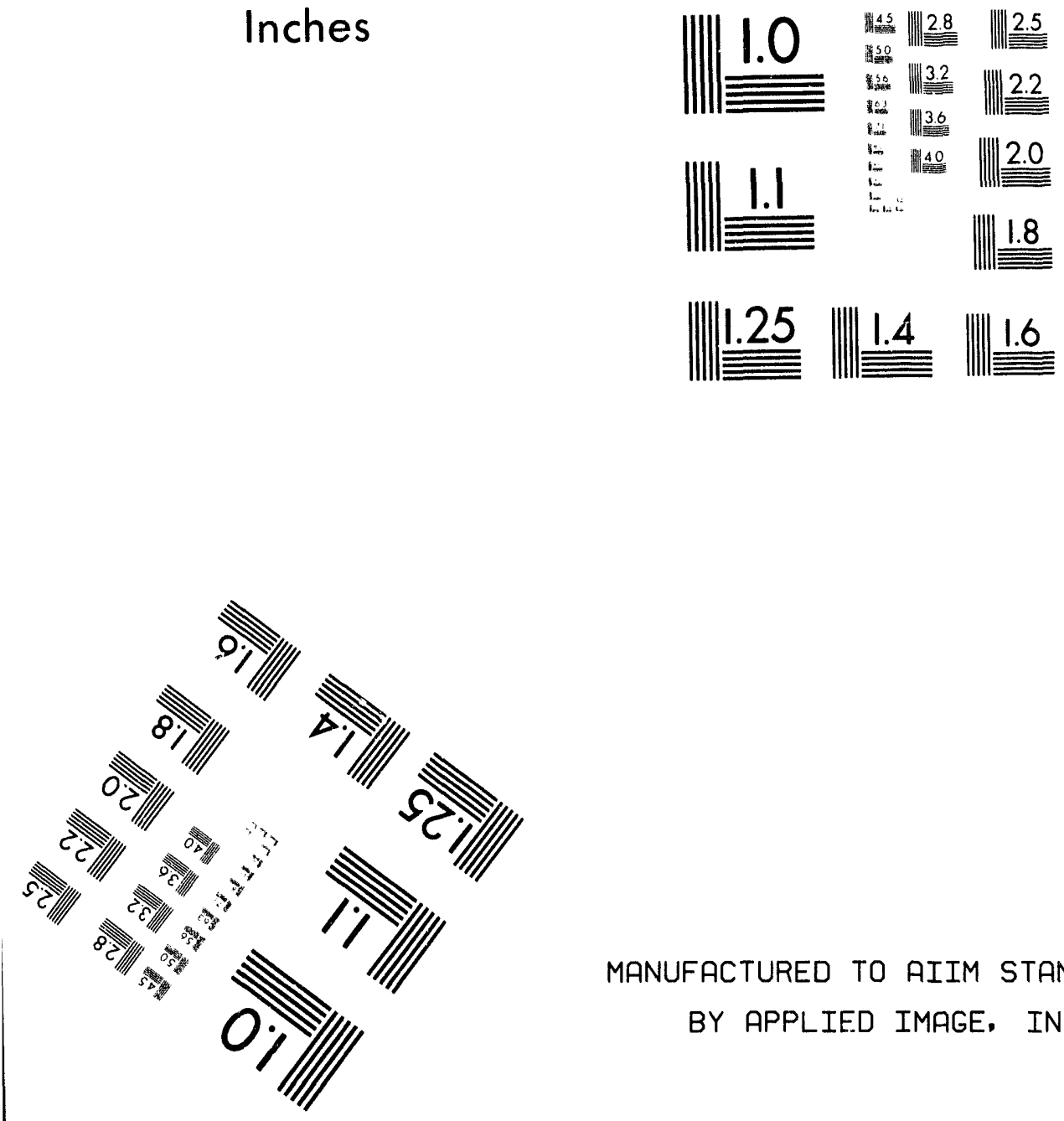

MANUFACTURED TO AIIM STANDARDS

BY APPLIED IMAGE, INC.

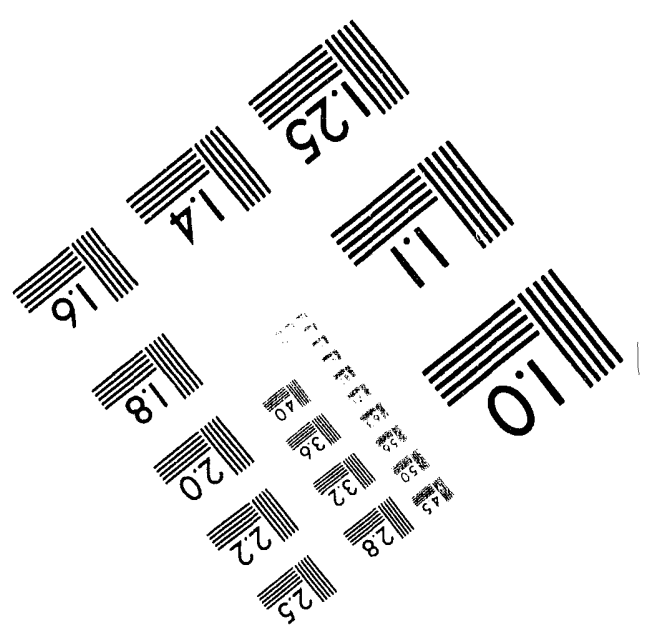



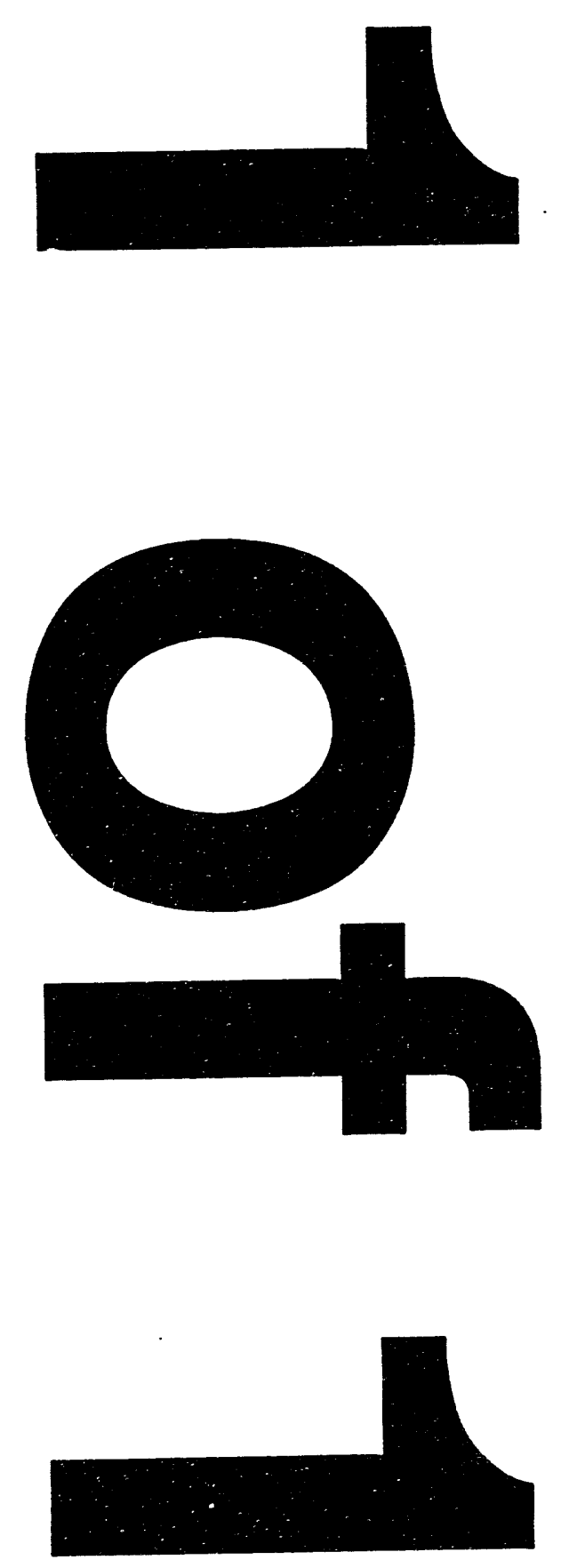


\author{
APPLICATION OF SPIN-SENSITIVE ELECTRON \\ SPECTROSCOPIES TO INVESTIGATIONS OF ELECTRONIC AND \\ MAGNETIC PROPERTIES OF SOLID SURFACES AND EPITAXIAL \\ SYSTEMS
}

Progress Report

1 November 1993 - 31 October 1994

G. K. Walters and F. B. Dunning

Rice University, Houston, TX 77251

May, 1994

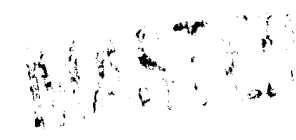

DISTRIBUTION OF THIS DOCUMENT IS UNLIMITED

$y^{2}$

\author{
PREPARED FOR THE U.S. DEPARTMENT OF ENERGY \\ UNDER GRANT NUMBER DE-FG05-86ER45233
}

\title{
DISCLAIMER
}

\begin{abstract}
This report was prepared as an account of work sponsored by an agency of the United States Government. Neither t'ie United States Government nor any agency thereof, nor any of their employees, makes any warranty, express or implied, or assumes any legal liability or responsibility for the accuracy, completeness, or usefulness of any information, apparatus, product, or process disclosed, or represents that its use would not infringe privately owned rights. Reference herein to any specific commercial product, process, or service by trade name, trademark, manufacturer, or otherwise does not necessarily constitute or imply its endorsement, recommendation, or favoring by the United States Government or any agency thereof. The views and opinions of authors expressed herein do not necessarily state or reflect those of the United States Government or any agency thereof.
\end{abstract}


Rice University

Progress Report

DoE Grant No. DE-FG05-86ER45233

\section{APPLICATION OF SPIN-SENSITIVE ELECTRON SPECTROSCOPIES TO INVESTIGATIONS OF ELECTRONIC AND MAGNETIC PROPERTIES OF SOLID SURFACES AND EPITAXIAL SYSTEMS}

Research during the current grant year has focused on:

(1) Measurements of the relative contributions of dipole- and impact-scattering to the energy loss spectrum of electrons backscattered from paramagnetic and ferrornagnetic metal surfaces, using Spin Polarized Electron Energy Loss Spectroscopy (SPEELS).

(2) Studies of the mechanisms whereby $\mathrm{He}\left(2^{3} \mathrm{~S}\right), \mathrm{He}\left(2^{1} \mathrm{~S}\right)$ and $\mathrm{He}\left(2^{3} \mathrm{P}\right)$ atoms are deexcited at $\mathrm{Ar}$ and Xe films deposited on metallic surfaces, using SpinPolarized Metastable (Atom) Deexcitation Spectroscopy (SPMDS).

(3) Development of a high-efficiency Mott polarimeter for use in Scanning Electron Microscopy with Polarization Analysis (SEMPA).

(4) Development of a low-energy spin polarized $\mathrm{He}^{+}$ion beam for magnetic imaging of surfaces and thin epitaxial films.

\section{SPEELS}

In these experiments, a beam of spin-polarized electrons is directed at the target surface and the energy- and angle-dependence of the spin polarization of electrons leaving the surface is measured for primary beam energies of $\sim 15$ to $150 \mathrm{eV}$.

Low energy ( $20-50 \mathrm{eV}$ ) electrons lose energy upon scattering from a metallic surface through two dominant processes - dipole-scattering in the vacuum outside the $\operatorname{target}^{1}$ and 
electron-hole $(\mathrm{e}-\mathrm{h})$ pair excitation (impact scattering) inside the target. ${ }^{2}$ Dipole-scattered electrons are expected to be concentrated around the specular scattering direction and preserve the full polarization of the incident beam since exchange scattering in the vacuum is not possible. In contrast, impact scattering (e-h pair excitation), which can lead to exchange, results in scattered electrons with approximately a cosine distribution about the surface normal. Angleand energy-resolved intensity and polarization measurements have yielded information on the relative contributions and angular distributions of dipole- and impact-scattered electrons. Data obtained from $\mathrm{Ag}, \mathrm{Cu}, \mathrm{Fe}$ and Mo surfaces are qualitatively consistent with expectations based on contributions from both dipole and impact scattering, but suggest that the angular distributions of scattered electrons resulting from these processes are not so different from one another as previously thought. Measurements now underway on a magnetized cobalt film grown epitaxially on $\mathrm{Cu}(100)$ are expected to yield the Stoner excitation spectrum when corrected for dipole scattering contributions. (Manuscript in preparation for Phys. Rev. B.)

\section{SPMDS}

In these studies, a beam of spin-polarized $\mathrm{He}\left(2^{3} \mathrm{~S}\right)$ metastable atoms is incident on the target surface, and we measure both the energy distribution and the energy dependence of the spin polarization of electrons ejected from the surface as a result of metastable atom deexcitation. Ejected electron energy distributions can also be measured for incident helium atoms excited to the $2^{1} \mathrm{~S}$ and $2^{3 \mathrm{P}}$ states. $^{3}$

Measurements of ejected electron energy distributions were used, in conjunction with electron spin labelling techniques, to probe the mechanisms by which $\operatorname{He}\left(2^{3} S\right), \operatorname{He}\left(2^{1} S\right)$ and $\mathrm{He}\left(2^{3} \mathrm{P}\right)$ atoms are deexcited at $\mathrm{Ar}$ and $\mathrm{Xe}$ films adsorbed on a cooled $\mathrm{Cu}(100)$ substrate. The data for both surfaces contain features similar to those observed in gas-phase Penning ionization indicating that ejection results, in part, from Auger deexcitation, i.e., surface Penning ionization. For Xe, however, additional features are observed that can be attributed to resonance ionization of an incident excited atom followed by neutralization of the resulting $\mathrm{He}^{+}$ion through an 
interaction that involves neighboring $\mathrm{Xe}$ atoms in the film. Indeed, the Xe data provide an exceptional example of a surface at which Auger deexcitation and resonance ionization occur in parallel with one another, with a branching ratio that changes significantly as the internal energy of the incident atoms increases. The ejected electron yield from both Ar and Xe films is substantially higher than for clean $\mathrm{Cu}(100)$ indicating that such films might form the basis of an efficient thermal-energy helium metastable atom detector. (Z. Physik, in press; Phys. Rev. A, in press)

\section{ELECTRON SPIN POLARIMETRY}

The SPMDS apparatus has also been used to develop a retarding-potential Mott polarimeter that, through the use of large-angle scattered electron detectors and careful optimization of the electron optics, provides much higher efficiencies than have been achieved previously with polarimeters of this type. The instrument is simple to construct, is stable in operation and has large electron optical acceptance. Its exceptional performance makes possible the development at Rice of Scanning Electron Spectroscopy with Polarization Analysis, ${ }^{4}$ proposed for the next funding cycle. (Rev. Sci. Instrum., in press)

\section{SPIN-POLARIZED $\mathrm{He}^{+}$ION BEAM}

A major new initiative is presently in the test phase, namely the development of a spinpolarized low-energy $\mathrm{He}^{+}$ion beam to be installed on the SPEELS apparatus. This will enable a new spin-sensitive electron spectroscopy - Spin Polarized Ion Neutralization Spectroscopy (SPINS) - that will permit us to image magnetic domain structure with high surface specificity. This initiative will exploit the recent discovery under this grant that the two electrons involved in Auger Neutralization of $\mathrm{He}^{+}$ions at $\mathrm{Cu}(100)$ and $\mathrm{Au}(100)$ surfaces have predominantly antiparallel spins. ${ }^{3}$ This strong spin-correlation can be used to measure the polarization of an incident $\mathrm{He}^{+}$beam. 
Spin-polarized $\mathrm{He}^{+}$ions can be extracted from a helium discharge in which $\mathrm{He}\left(2^{3} \mathrm{~S}\right)$ atoms are produced and then spin-polarized by optical pumping, as was demonstrated some years ago by one of us (GKW). ${ }^{6}$ However, until now, there was no known method for measuring the beam spin polarization at low energies.

In imaging applications, the beam is scanned and the size of the focussed ion beam spot (and thus spatial resolution) will be governed by a number of factors including the source emittance and the final beam erergy and divergence at the target. Although the polarized ion source is still in the initial phases of its development, it is reasonable to expect that spatial resolutions of $\sim 1$ to $10 \mu \mathrm{m}$ can be obtained which, while less than can be achieved by SEMPA, are sufficient for imaging many domain structures.

\section{PUBLICATIONS}

"Probing the Surface-Vacuum Interface With Spin-Sensitive Metastable Atom Deexcitation, Electron Capture and Electron Emission Spectroscopies," G. K. Walters and C. Rau, Materials Research Society Symposium Proceedings, 313, 527 (1993).

"Use of Spin-Labelling Techniques to Probe the Dynamics of $\mathrm{He}\left(2^{3} \mathrm{~S}\right)$ Deexcitation at Solid Surfaces," F. B. Dunning, D. M. Oró, P. A. Soletsky, X. Zhang, P. Nordlander, and G. K. Walters, Z. für Physik, in press.

"Deexcitation of $\mathrm{He}\left(2^{3} \mathrm{~S} ;, \mathrm{He}\left(2^{1} \mathrm{~S}\right)\right.$ and $\mathrm{He}\left(2^{3} \mathrm{P}\right)$ Atoms at $\mathrm{Ar}$ and Xe Films," D. M. Oró, P. A. Soletsky, X. Zhang, F. B. Dunning and G. K. Walters, Phys. Rev. A, in press.

"High Efficiency Retarding-Potential Mott Polarization Analyzer," G. C. Burnett, T. J. Monroe and F. B. Dunning, Rev. Sci. Instrum., in press. 


\section{INVITED TALKS}

"Use of Spin-Labelling Techniques to Probe the Dynamics of $\mathrm{He}\left(2^{3} \mathrm{~S}\right)$ Deexcitation at Solid Surfaces," 7 th International Symposium on Polarization and Correlation in Electronic and Atomic Collisions, Bielefeld, Germany, July 1993. (F. B. Dunning)

"Mott Electron Polarimetry," 8th National Conference on Synchrotron Radiation Instrumentation, NIST, Gaithersburg, August 1993. (F. B. Dunning)

"Use of Polarized Electrons and ${ }^{4} \mathrm{He}$ Metastable Atoms in Surface Physics," Les Houches Workshop on Polarized Beams and Targets, Les Houches, France, June 1994. (G. K. Walters) "Spin Dependent Studies of the Dynamics of Metastable Helium Deexcitation Near Surfaces," Inelastic Ion-Surface Collisions Workshop 10, Grand Targhee, Wyoming, August 1994. (F. B. Dunning)

\section{PERSONNEL}

D. M. Oró was awarded his Ph.D. degree in May 1994 and accepted a postdoctoral position at Los Alamos National Laboratory. Maurice Magugumela and Gregory Burnett received their M.A. degrees in May 1994. Magugumela is now undertaking his Ph.D. research. Burnett will continue his education elsewhere.

\section{REFERENCES}

1. D. L. Mills, Surface Science 48, 59 (1975).

2. X. Zhang, H. Hsu, F. B. Dunning and G. K. Walters, Phys. Rev. B 44, 9133 (1991).

3. D. M. Oró, Q. Lin, P. A. Soletsky, X. Zhang, F. B. Dunning and G. K. Walters, Phys. Rev. B 46, 9893 (1992).

4. J. Unguris, G. G. Hembree, R. J. Celotta and D. T. Pierce, J. Magn. Magnetic Mater. 54-57, 1629 (1986).

5. S. D. Baker, E. B. Carter, D. O. Findley, L. L. Hatfield, G. C. Phillips, M. D. Stockwell and G. K. Walters, Phys. Rev. Lett. 20, 738 (1968). 


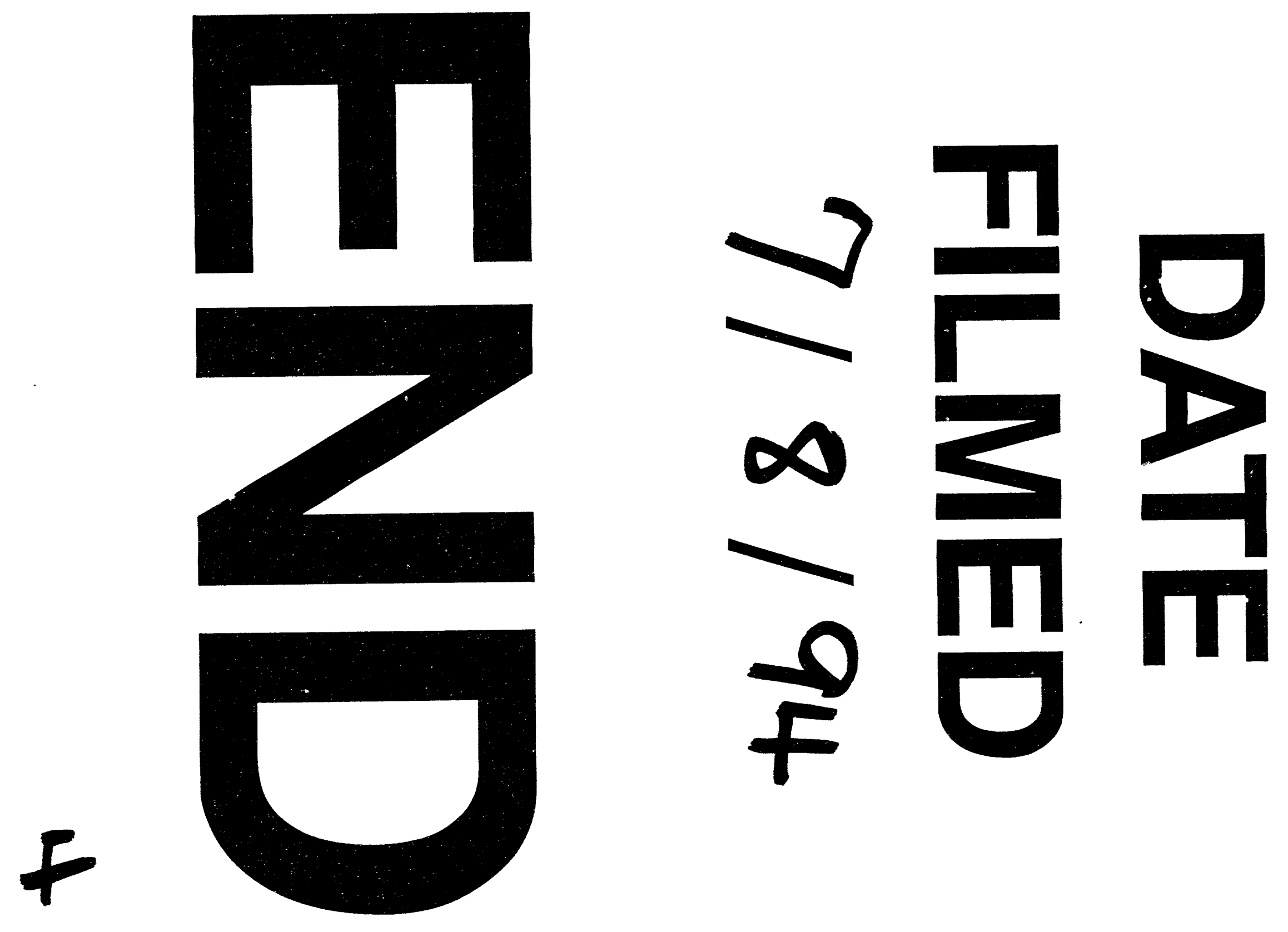


